\title{
Observing the Status of Women Through Health System Interactions
}

\author{
Kristina Baier ${ }^{1}$ \\ ${ }^{1}$ Faculty of Medicine, University of Ottawa
}

\section{ABSTRACT}

This elective report provides an overview of the challenges women in Bolivia face when accessing care for reproductive health reasons. The perspectives provided in this paper are from the viewpoint of a Canadian medical student, after completing a 4-week elective in obstetrics and gynecology. Examples within obstetrics, gynecology, and obstetrical violence are used to provide insight into personal reflections regarding the status of women, observed during clinical encounters with patients and staff in a women's hospital.

\section{RÉSUMÉ}

Ce rapport de stage fournit un aperçu des défis auxquels sont confrontées les femmes en Bolivie lorsqu'elles accèdent à des soins pour des raisons de santé génésique. Les points de vue présentés dans ce document sont du point de vue d'une étudiante en médecine canadienne, après avoir terminé un stage de quatre semaines en obstétrique et en gynécologie. Des exemples d'obstétrique, de gynécologie et de violence obstétricale sont utilisés pour donner un aperçu des réflexions personnelles concernant la condition de la femme, observées lors des rencontres cliniques avec les patients et le personnel d'un hôpital pour femmes.

I arrived at the entrance of a woman's hospital in Bolivia with baggage. Metaphorically speaking, I arrived with my values, my opinions, and my experiences. Prior to my elective, as I was beginning to establish a foundation in health advocacy by learning to harness my skills and competencies, I found myself questioning our roles in health advocacy beyond our national borders. I wanted to ensure I was taking an ethical approach to this elective. My objectives were to observe and learn, not to teach. I came equipped with my own supplies and prophylaxis to minimize the 'medical footprint' I was to leave behind. My work was cemented in the notion of health as a human right, which included the right to quality health services. I recognized my limitations as a medical student, and refused to advance my technical skills at the expense of a patient and their safety.

My approach to this elective stemmed from my interest in a holistic approach to healthcare for a vulnerable population: women. Bolivia harbours one of the highest maternal mortality rates in Latin America [1]. I completed my elective at a tertiarylevel hospital dedicated to women's health, where I hoped to acquire knowledge on the triumphs and tribulations facing women regarding their reproductive care.

\section{OBSTETRICS}

The emergency department was set up to maximize efficiency. Protocol disallowed family from entering the department and accompanying women during labour and delivery. This protocol is contrary to what I have observed in Canada, where labouring women are often accompanied by their partners or other support systems. The delivery room had four beds with cracks in the synthetic materials covering the thin padding; each bed was adorned by stirrups and separated by a curtain. Women were triaged, then escorted to either the dilation or pre-operative rooms for monitoring, or to a room designated for manual vacuum aspiration.

Systemically, Bolivia has public and private health centres. In private clinics, women with the ability to pay can deliver their babies in private rooms, in the presence of their loved ones. At this public hospital, family members waited outside, often spending the night on plastic benches or on the cobblestone.

Each vaginal delivery had a synchronicity to it. The patient was ushered from the dilation room onto a gurney, and helped onto the delivery table. A roll of cotton covered in paper packaging was placed under the patient's neck. She was ordered to rest her legs onto the stirrups, and position her hands around the

Keywords: Bolivia; Obstetrics; Gynecology; Reproductive Health; International Elective 
vertical metal bars currently supporting her bent knees. After she delivered, it was time to lower the head of the bed, unroll the packaged cotton, and place it between her legs, and remove her legs from the stirrups. Epidurals were only provided to women undergoing a caesarean section, demonstrating the differences in pain management options compared to Canada and perhaps explained by disparities in resource availability, feasibility, and accessibility.

\section{GYNECOLOGY}

My first day at the hospital coincided with the first day of the staff strike. Mattresses were placed on the floor of the hospital entrance. I would often hear protestors chanting for better working conditions and benefits. Various women's health services were temporarily unavailable. The strike ended less than two weeks later, and external consultations resumed.

Although I witnessed the stagnation of health services when non-physicians went on strike, I also observed physicians go on strike. I was scheduled to work with a physician in external consultations one morning. I arrived to an empty waiting area. The physician cancelled his clinic, as he was on strike. This cancellation meant that many women would not be receiving their Papanicolaou smears. When he resumed clinical duties the following day, I saw women in their forties come for their first Papanicolaou smears.

Unfortunately, many cases are lost to follow-up, where patients do not return within the recommended timeframe. Although Bolivian and Canadian health systems strive to screen women for cervical cancer within suggested periods, I noticed that the average age at first presentation for cervical cancer screening was older in Bolivia than in Canada. A medical student highlighted the fact that the limited primary healthcare system stems from the notion that the presence of symptoms is what drives people to seek medical attention; thus, preventative medicine is neglected for more symptomatic presentations.

\section{VIOLENCE AGAINST WOMEN IN HOSPITALS}

Actions of abuse or disrespect by health professionals prenatally, during labour and delivery, or postnatally in facility-based childbirths is known as obstetrical violence [2]. My first experiences witnessing obstetrical violence occurred during this elective, and I realized how unprepared I was to challenge these violations as a foreign medical student and health advocate.
Discrimination from physicians was often in the form of verbal comments. I was rounding with a physician in the post-operative wing. If a patient had six or more children, the physician said they needed to 'ligate themselves', or that they 'needed to be more responsible'. These comments placed blame on women for their family size. Restrictions in reproductive health exist in Bolivia and produce barriers for women to ascertain their reproductive health rights. There were no conversations about the root causes of unwanted pregnancies in Bolivia, nor about the targeting of social inequalities, and gender-based violence that engender these outcomes.

Furthermore, a vulnerable sub-population are adolescent mothers. I interacted daily with adolescent patients, many of whom delivered their babies by caesarean section. To demonstrate the pervasiveness of adolescent pregnancies in Bolivia, the adolescent fertility rate, for women aged $15-19$, was 70 births per 1,000 women in 2015. Canada's adolescent fertility rate in the same year was 9 births per 1,000 women [3].

I recall standing by a patient's bedside. The mother was holding her newborn, and the doctor turned to me and asked, "How old do you think she is?"The patient looked down, and I sensed sadness and shame. I believed that the emphasis made by the physician on her young age was afflicting her emotionally. I felt uncomfortable wearing my white coat, as I thought that this piece of fabric was engendering negative emotions in a patient based on the judgements of other providers at her expense. The most challenging experiences occurred when health professionals neglected the compassionate art of medicine for a more discriminatory approach to patient interactions. This incident was not an isolated event during my elective. These experiences provided insight into the treatment of a vulnerable population of women. My intentions are not to subject the health system, nor its members to scrutiny; however, I believe that treating patients in a humanistic matter is ethical, irrespective of national borders.

Obstetrical violence is not isolated to a specific country. Reports have also been published on cases of obstetrical violence in North America [4]. As health advocates, our role is to challenge systemic abuses and injustices faced by our patients, and by society. Although I felt unprepared to exercise my role as a health advocate in a foreign country, this elective has provided me with the opportunity to grow and expand my competencies as a future advocate in both national and international areas. I 
hope to incorporate health advocacy as a cornerstone to my future practice. No country is immune to the tyranny of injustice, and with human rights transcending international borders, individuals can advocate at both national and international levels when done professionally and ethically.

\section{FINAL REFLECTIONS}

Reflections from my elective that I hold dear are not merely the techniques I observed nor the medical vocabulary I acquired. Rather, it is the privilege of being granted insight into women's health services in a system different from my own. The macrosystemic effects on the status of women percolate down all echelons of civil society and infiltrate into the care provided to women. I realized that concepts surrounding women's reproductive health in Bolivia are not openly discussed. And as a result, many of the abuses and realities surrounding reproductive health remain untold.

\section{REFERENCES}

1. Hill K, Thomas K, AbouZahr C, et al. Estimates of maternal mortality worldwide between 1990 and 2005: An assessment of available data. Lancet. 2007;370(9595):1311-9.

2. World Health Organization. The prevention and elimination of disrespect and abuse during facility-based childbirth. [Internet]. Geneva (CHE): World Health Organization; 2015 [updated 2015; cited 2017 Oct 25]. Available from: http://apps.who.int/iris/bitstream/10665/134588/1/WHO_ RHR_14.23_eng.pdf.

3. World Bank. Adolescent fertility rate (births per 1,000 women ages 15-19). [Internet]. Washington D.C. (USA): World Bank Group; 2015 [updated 2015; cited 2017 Sept 29]. Available from: https://data.worldbank.org/indicator/ SP.ADO.TFRT.

4. Diaz-Tello F. Invisible wounds: obstetric violence in the United States. Reprod Health Matters. 2016;24(47):56-64. 